\title{
Transcatheter Retrograde Device Closure of an Isolated Pulmonary Valve Stump Using a Deflectable Sheath Technique
}

\author{
John F. Rhodes, MD', Amanda S. Green, FNP-C', Robert D.B. Jaquiss, MD² \\ ${ }^{1}$ Miami Children's Health System, Department of Cardiology, Miami, Florida, USA \\ ${ }^{2}$ University of Texas Southwestern Medical Center, Department of Cardiovascular \& Thoracic Surgery, Dallas, Texas, USA
}

\begin{abstract}
Patients with a single ventricular heart physiology may have a persistent egress through one of the semilunar valves that was surgically closed during the palliative operations. This semi lunar patency results in a blind ending pulmonary artery stump. Consequently, the patient is at risk for thrombus that can then result in a paradoxical embolic event and potentially an ischemic stroke. Patients therefore must undergo a reoperation to close the stump or remain on anticoagulation for lifetime. This report demonstrates the use of a retrograde arterial approach and a deflectable delivery sheath to obliterate the proximal pulmonary valve with a vascular device.
\end{abstract}

\section{Key Words}

Stroke - Pulmonary valve - Device closure - Single ventricle • Embolic events

\section{Introduction}

The surgical palliation of children with univentricular hearts without obstruction to pulmonary outflow consists of either Damus-Kaye-Stansel anastomosis of the two great vessels in the setting of potentially obstructed systemic outflow or division of the pulmonary artery leaving the aorta as the sole outflow pathway if there is no potential for subaortic obstruction [1]. If the latter approach is elected, the

(c) 2017 Journal of Structural Heart Disease Published by Science International Corp. ISSN 2326-4004 technique of pulmonary artery division must minimize the potential for thrombus formation in the blind ending pulmonary artery stump and subsequent risk for systemic embolic events $[2,3,4]$. In the event that such a stump is present, anticoagulation may be employed $[5,6,7]$, but if thrombus develops within the stump or embolism occurs, an intervention to exclude the stump may be required. Here, we describe a novel management strategy in such a circumstance and present long-term follow-up information.

\section{Case Presentation}

The original cardiac anatomy of our patient was that of a functionally univentricular heart. There was (right-sided) mitral atresia, a large secundum atrial septal defect, and a large outlet ventricular septal defect. The aorta arose from the anterior and leftward (morphologic right) ventricle and was unobstructed, as was the aortic arch. The pulmonary artery arose from the rightward and posterior (morphological left) ventricle and had significant valvar and subvalvar obstruction, such that the patient had prostaglandin-dependent pulmonary blood flow (Figure 1).

As a neonate, via sternotomy, the patient underwent construction of a right-sided modified Blalock-Taussig shunt using a 4-mm-diameter graft. The ductus arteriosus was not ligated at that time

${ }^{*}$ Corresponding author:

John F. Rhodes, Jr., MD

Department of Cardiology

Miami Children's Health System

3100 SW 62 Avenue, Miami, Florida 33155, USA

Tel.: +1 305662 8301; Fax: +1 305662 8304; E-Mail: jfrhodes47@gmail.com 


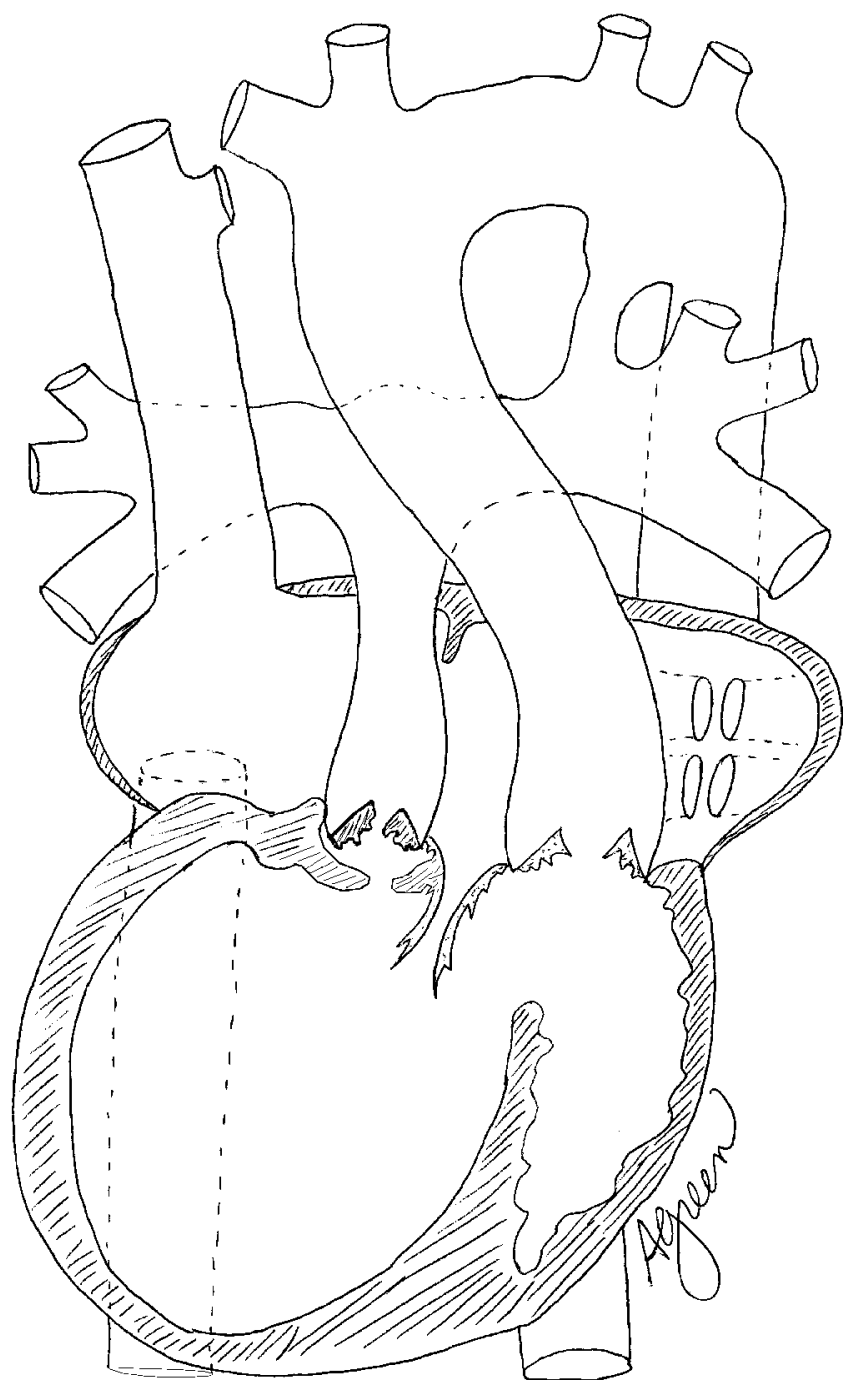

Figure 1. Schematic of the single ventricle anatomy prior to surgical intervention.

and later closed spontaneously. At 6 months of age, via re-do sternotomy, the patient underwent shunt takedown and construction of a bidirectional Glenn anastomosis. The main pulmonary artery was not divided but was suture-ligated proximally. Follow-up echocardiography revealed persistent patency of the main pulmonary artery. At 30 months of age, via third-time sternotomy, an extracardiac Fontan operation was performed using a $20-\mathrm{mm}$ conduit. The main pulmonary artery was again suture-ligated but not divided, leaving a blind end pulmonary outflow stump (Figure 2).

An echocardiogram performed on post-operative day 5 demonstrated persistent to-and-from flow into

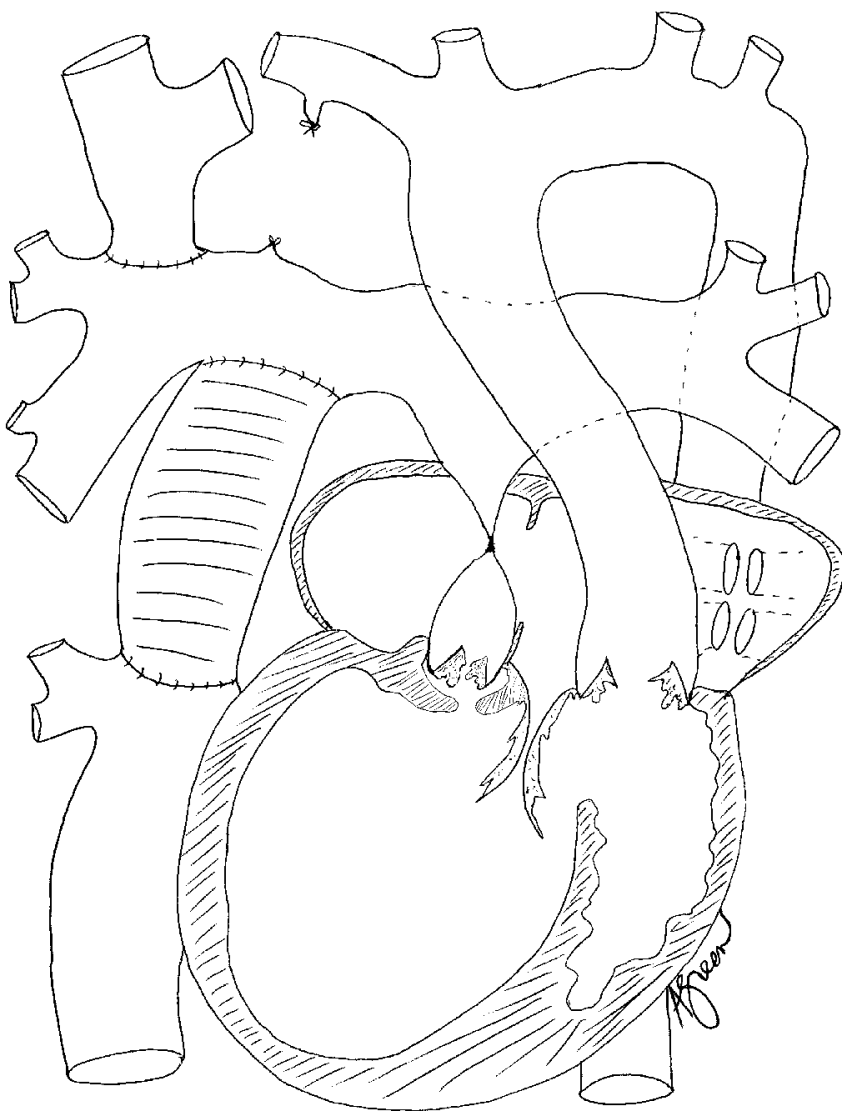

Figure 2. Schematic of the single ventricle anatomy after the Fontan operation.

the proximal pulmonary artery but no antegrade flow into the pulmonary arteries or Fontan circuit (Figure 3). Although no thrombus was appreciated within the pulmonary valve sinuses or proximal pulmonary artery, the patient was started on warfarin therapy. A follow-up echocardiogram two months later demonstrated a moderate-sized mobile thrombus within the pulmonary stump despite an international normalized ratio of 3.3. Although there was no evidence of systemic embolism, it was deemed necessary to proceed with obliteration of the pulmonary stump, as the presence of thrombus was felt to indicate failure of anticoagulation therapy. Because of the patient's recent surgery and multiple prior procedures, transcatheter obliteration was proposed.

At nearly 3 years of age and a weight of $18 \mathrm{~kg}$, the patient proceeded to the cardiac catheterization laboratory. The procedure was performed under general anesthesia guided by transesophageal echocardiog- 
A

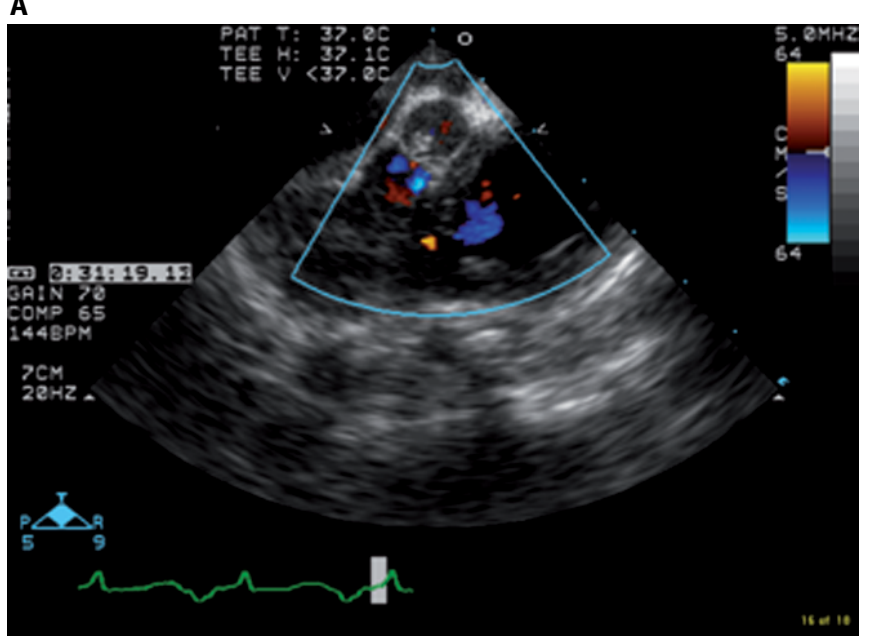

B

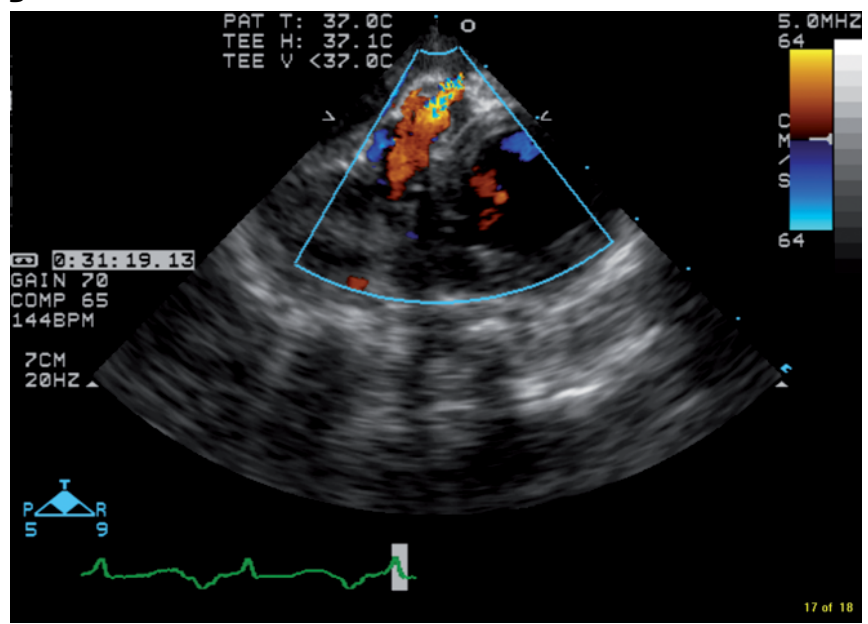

Figure 3. Transthoracic echocardiogram color-flow Doppler image on post-operative day 5 after the Fontan operation. (Panel $A$ ) Evidence of persistent to-and-from flow into the proximal pulmonary artery stump. (Panel B) No evidence of significant antegrade flow across the sutured main pulmonary artery into the Fontan circuit.

raphy and fluoroscopy. Vascular access consisted of a 5-F percutaneously-placed sheath in the left femoral artery. Angiography of the femoral arterial system confirmed an appropriate vessel diameter of $4.2 \mathrm{~mm}$ for upsizing the arterial sheath. From the left femoral artery sheath, a 5-F pigtail catheter was positioned using a 0.035 -in J wire across the aortic valve and through the ventricular septal defect into the right-sided morphologic left ventricle. Subsequently, a 0.032-in J wire was positioned through the 5-F pigtail, and an 8.5-F (internal diameter) Agilis steerable sheath (St. Jude Medical, St. Paul, Minnesota) was positioned over the 0.032-in $\mathrm{J}$ wire and into the mid-right-sided morphological left ventricular cavity. The Agilis sheath was deflected to allow an angle directly toward the pulmonary valve (Figure 4). During this maneuver, there was a brief $(<3 \mathrm{~s})$ episode of transient complete heart block with no hemodynamic changes. Subsequently, a 6-F multipurpose A-1 catheter was advanced through the Agilis sheath and positioned immediately distal to the pulmonary valve apparatus for an angiogram (Figure 5). Subsequently, a 0.038-in standard J-wire was advanced into the proximal pulmonary artery, and the 6- $\mathrm{F}$ multipurpose catheter was removed. A 6-F JL 3.5 coronary guide catheter was inserted over this wire into the pulmonary valve stump. This wire was removed, and the coronary guide catheter was used to position a 12mm Amplatzer Vascular Plug (St. Jude Medical) across the pulmonary valve apparatus. The device was fully deployed with a waist in the mid-portion (Figure 6), suggesting engagement with the pulmonary valve annulus. A ventriculogram demonstrated a well-positioned device and no evidence of flow into the pulmonary valve or pulmonary artery (Figure 7). Subsequent angiography and transesophageal echocardiography demonstrated no significant leak around the device but a trivial leak through the device mesh. The previously noted thrombus material remained within the pulmonary outflow stump, with thrombus egress prevented by the device. The femoral arterial sheath was removed, periprocedural antibiotics were administered, aspirin and warfarin were restarted, and there were no unanticipated adverse events.

The patient was maintained on warfarin and aspirin post-procedure. An early pre-discharge transthoracic echocardiogram demonstrated that the vascular occlusion device was in a good position across the pulmonary valve with elimination of leaflet motion. A trace amount of prograde flow by color-flow Doppler was observed through the device mesh without reflux back across the valve leaflets. The previously noted thrombus remained along the posterior wall of the pulmonary stump. After 6 months, warfarin was discontinued, and aspirin was continued indefinitely. No evidence of thrombus recurrence or propagation was detected, nor was there any sign of systemic embolism. 
A

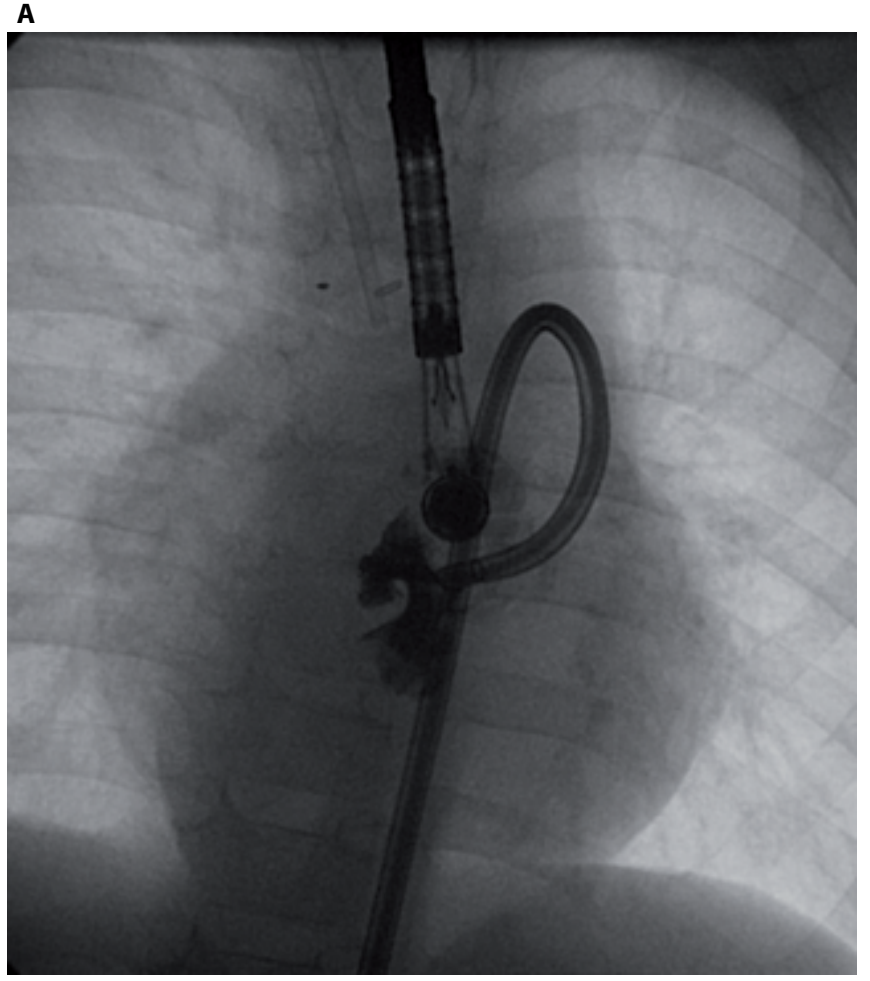

B

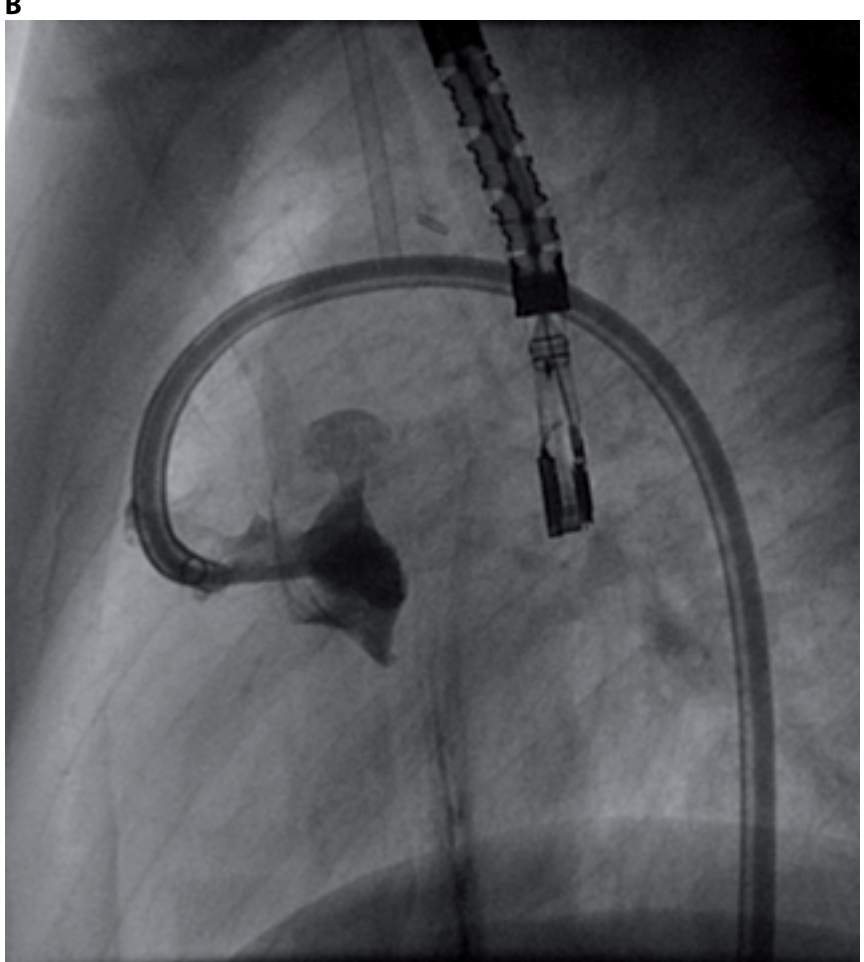

Figure 4. Agilis sheath retrogradely placed into the left ventricle and deflected toward the pulmonary valve. (Panel A) Anterior-posterior projection. (Panel A) Lateral projection.

A

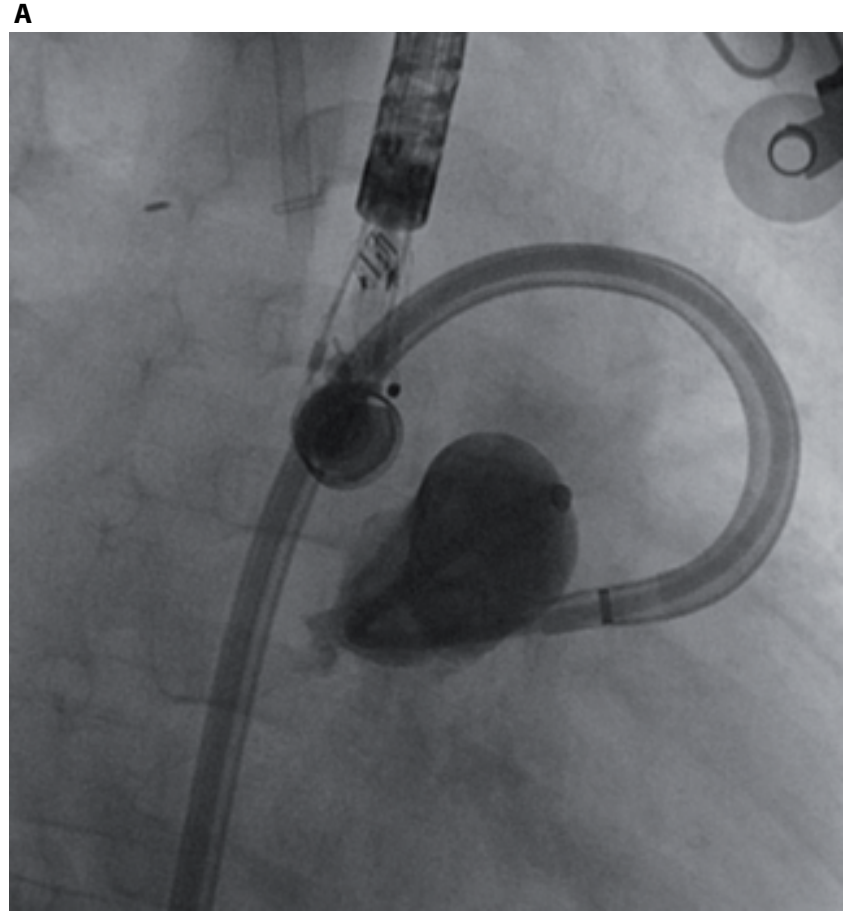

B

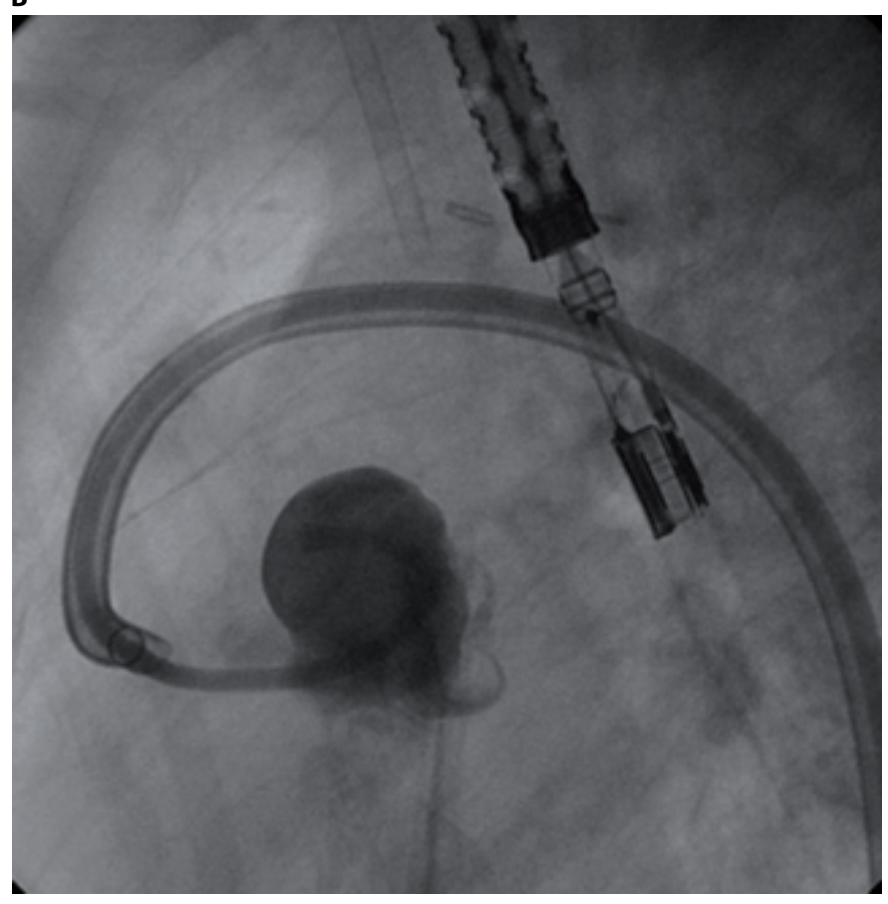

Figure 5. A 6-F multipurpose A-1 catheter advanced through the Agilis sheath and positioned immediately distal to the pulmonary valve apparatus for an angiogram. (Panel A) Right anterior oblique projection. (Panel B) Lateral projection. 
A

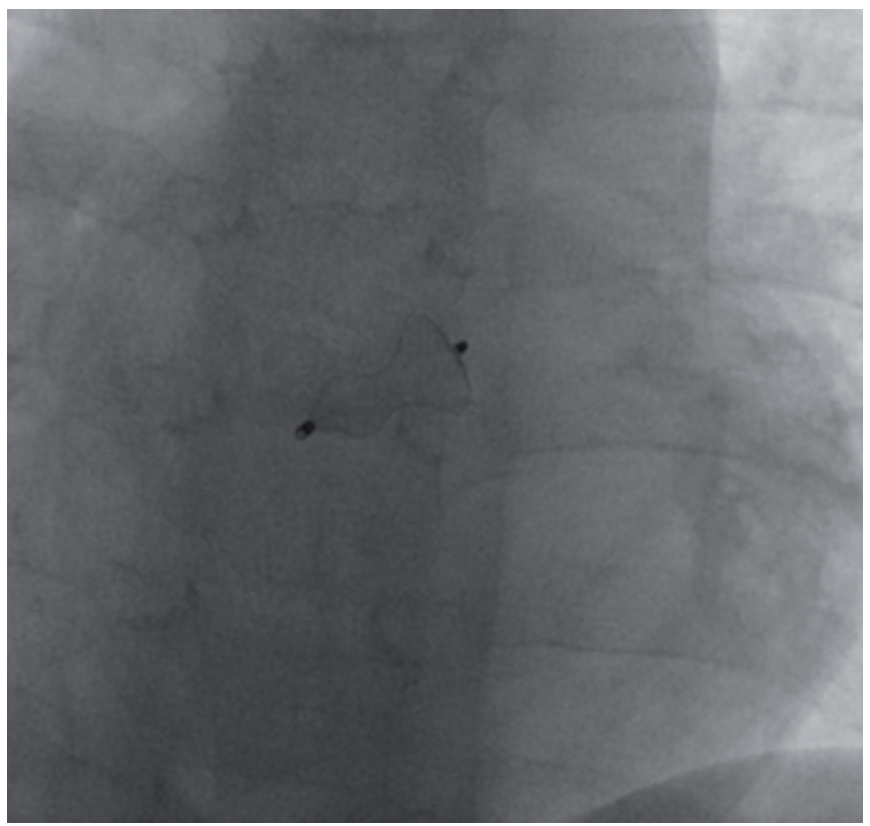

B

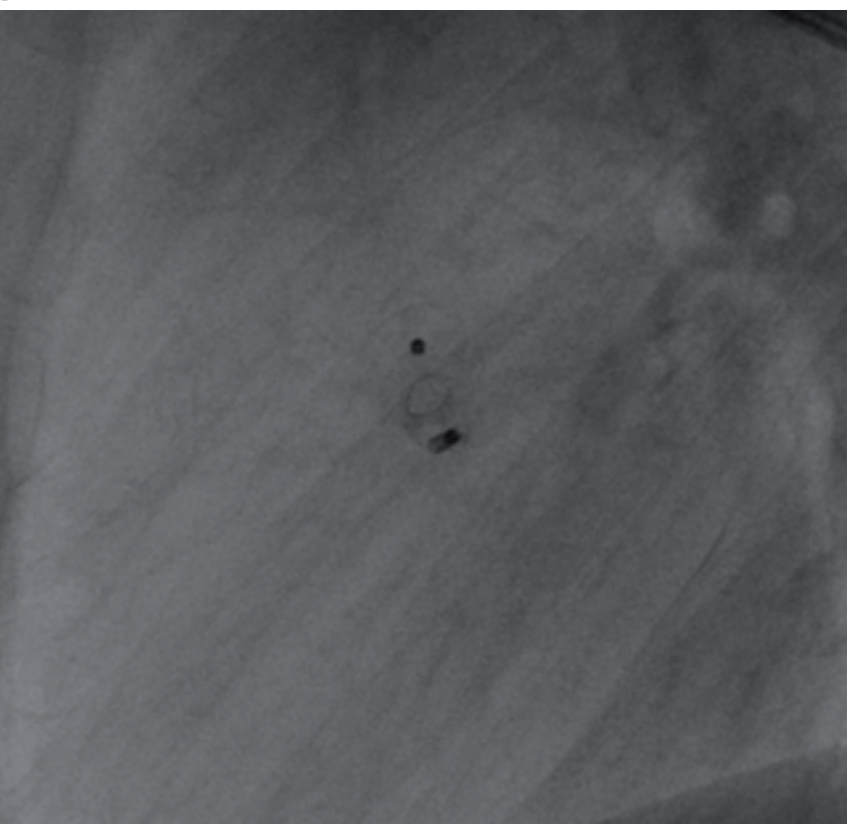

Figure 6. A 12-mm Amplatzer Vascular Plug fully deployed with a waist in the mid-portion across the pulmonary valve apparatus. (Panel A) Anterior-posterior projection. (Panel B) Lateral projection.

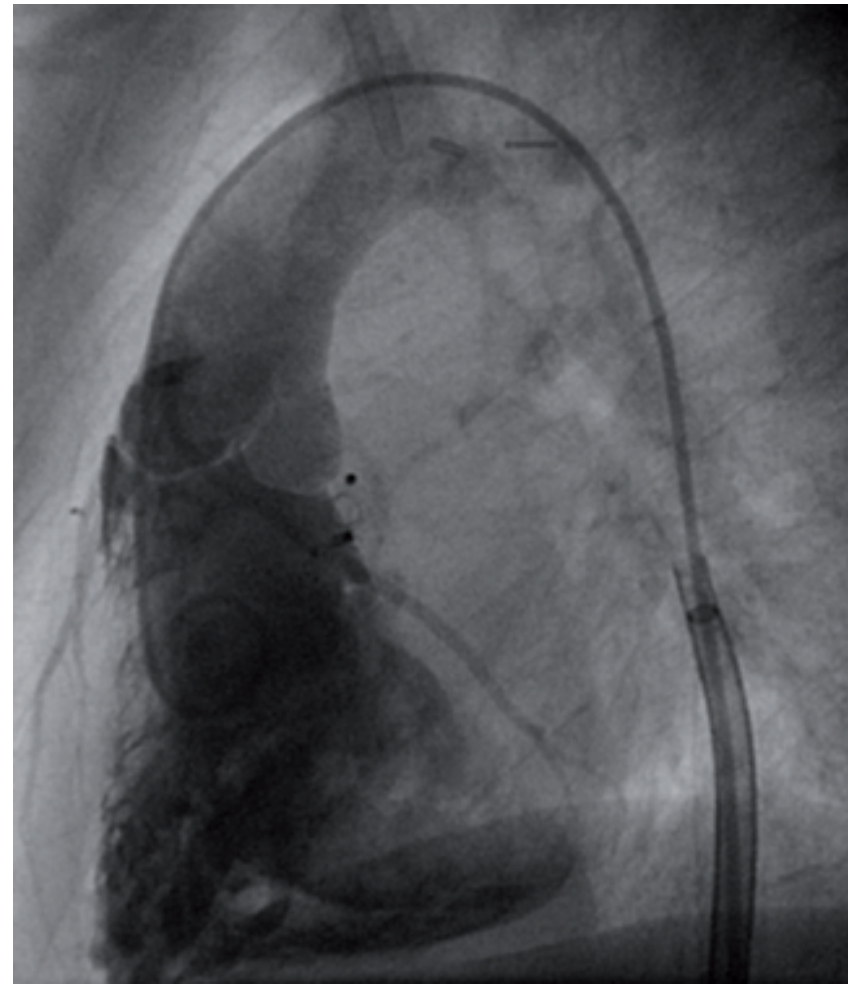

Figure 7. Ventriculogram demonstrating a well-positioned Amplatzer Vascular Plug and no evidence of flow into the pulmonary valve or pulmonary artery.

Journal of Structural Heart Disease, August 2017
The echocardiogram at the most recent follow-up of 7 years demonstrated a well-positioned vascular device and no residual flow into or out of the proximal pulmonary artery (Figure 8). This finding was confirmed by magnetic resonance imaging angiography with and without contrast, though the images were partially obscured by an artifact related to the occlusion device. In addition, at the most recent follow-up, there was no leg length discrepancy and normal femoral pulses bilaterally.

\section{Discussion}

We believe this to be the first report of the use of a percutaneous retrograde deflectable sheath technique and vascular occluder to obliterate the proximal pulmonary artery in this setting. There are reports of perventricular approaches to close the pulmonary artery stump [8] as well as multiple publications describing vascular occluders for other indications including AV malformations, aorto-pulmonary collaterals, and coronary fistula [9].

This indication should be relatively rare, as the pulmonary valve is often resected and the proximal pulmonary trunk obliterated with suture lig- 
A

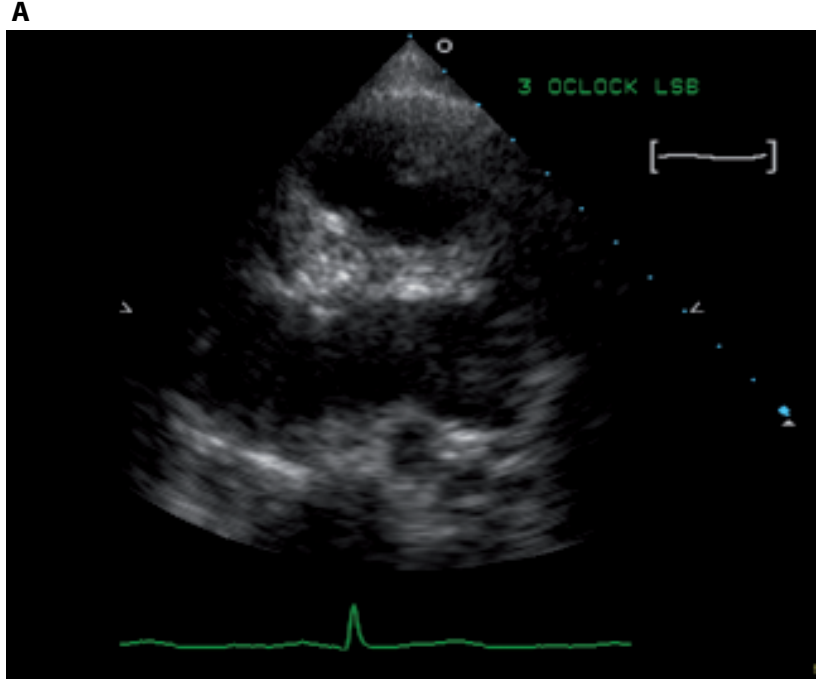

B

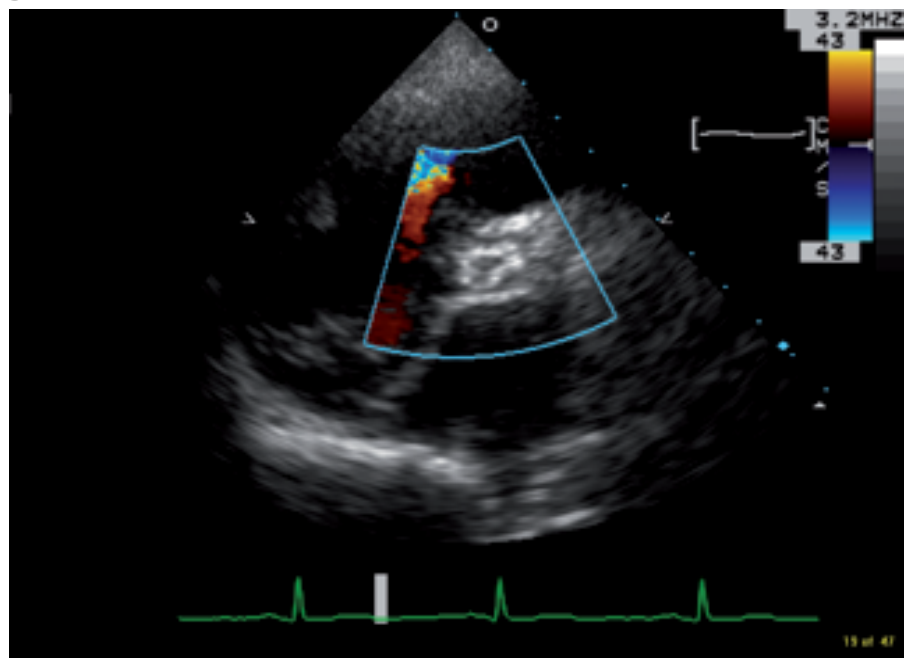

Figure 8. Transthoracic echocardiogram with color-flow Doppler at 7-year follow-up demonstrated a well-positioned vascular device and no residual flow into or out of the proximal pulmonary artery. (Panel A) Two-dimensional imaging. (Panel B) Color-flow Doppler imaging.

ature during staged palliation. However, in some cases, the surgeon may not perform these maneuvers, perhaps because of the presence of important coronary artery branches around the pulmonary annulus or the wish to preserve additional pulmonary blood flow at the time of the Glenn operation. In such circumstances, thrombus may develop within the proximal pulmonary artery immediately distal to the pulmonary valve apparatus [7]. If this is recognized, the patient may be treated with long-term anticoagulation [5]. With valve patency, and particularly to-and-from flow across the pulmonary valve, a thrombus may dislodge into the systemic circulation $[2,3,4]$ and result in stroke $[2,3]$, with significant consequent morbidity and even mortality [7]. When thrombus is identified or suspected, the most aggressive approach would include surgical thrombectomy and patch closure of the pulmonary annulus. As this would require what in most children would be fourth sternotomy, as well as the use of cardiopulmonary bypass, a trial of medical therapy may be undertaken. If that fails or is felt unlikely to be successful, we have demonstrated an effective alternative to surgery. Also, perventricular techniques should be considered if the femoral arterial system is deemed inadequate for the large deflectable sheath.

In conclusion, this report demonstrates the use of a retrograde arterial approach and a deflectable delivery sheath to obliterate the proximal pulmonary valve with a vascular device, thus precluding the need for reoperation, perventricular technique, or lifetime anticoagulation and associated risks. Transcatheter obliteration of a blind ending pulmonary artery stump is feasible and durably effective.

\section{Conflict of Interest}

The authors have no conflict of interest relevant to this publication.

\section{Comment on this Article or Ask a Question}




\section{References}

1. Khairy P, Fernandes SM, Mayer JE Jr, Triedman JK, Walsh EP, Lock JE, et al. Long-term survival, modes of death, and predictors of mortality in patients with Fontan surgery. Circulation. 2008;117:85-92. DOI: 10.1161/ CIRCULATIONAHA.107.738559

2. du Plessis AJ, Chang AC, Wessel DL, Lock JE, Wernovsky G, Newburger JW, et al. Cerebrovascular accidents following the Fontan operation. Pediatr Neurol. 1996;12:230-236. PMID: 7619190

3. Oski JA, Canter CE, Spray TL, Kan JS, Cameron DE, Murphy AM. Embolic stroke after ligation of the pulmonary artery in patients with functional single ventricle. Am Heart J. 1996;132:836-840. PMID: 8831374

4. Koide M, Abe M, Kodera K, Sudo K, Seguchi $M$, Sakai A. Thromboembolism originating from the pulmonary artery stump after
Fontan operation. Jpn J Thorac Cardiovasc Surg. 1999;47:346-349.

5. Cheung YF, Chay GW, Chiu CS, Cheng LC. Long-term anticoagulation therapy and thromboembolic complications after the Fontan procedure. Int J Cardiol. 2005;102:509513. DOI: 10.1016/j.ijcard.2004.05.051

6. Yie $\mathrm{K}$, Lee $\mathrm{CH}$, Kim SJ. Thrombi in the main pulmonary artery stump after a Fontan operation. Pediatr Cardiol. 2008;29:870-871. DOI: 10.1007/s00246-007-9190-z

7. Lee SY, Baek JS, Kim GB, Kwon BS, Bae EJ, Noh $\mathrm{Cl}$, et al. Clinical significance of thrombosis in an intracardiac blind pouch after a Fontan operation. Pediatr Cardiol. 2012;33:42-48. DOI: 10.1007/s00246-011-0074-x

8. Darby $S$, llbawi $M$, Amin Z. Perventricular closure of pulmonary stump in a 16-kg child. Catheter Cardiovasc Interv. 2015;85:271-273. DOI: 10.1002/ccd.25497
9. Schwartz M, Glatz AC, Rome JJ, Gillespie MJ. The Amplatzer vascular plug and Amplatzer vascular plug II for vascular occlusion procedures in 50 patients with congenital cardiovascular disease. Catheter Cardiovasc Interv. 2012;76:411-417. DOI: $10.1002 /$ ccd. 22370

Cite this article as: Rhodes JF, Green AS, Jaquiss RDB. Transcatheter Retrograde Device Closure of an Isolated Pulmonary Valve Stump Using a Deflectable Sheath Technique. Structural Heart Disease. 2017;3(4):128-134. DOI: https://doi. org/10.12945/j.jshd.2017.005.17 